\title{
Frequency and determinants of vitamin D deficiency among premenopausal and postmenopausal women in Karachi Pakistan
}

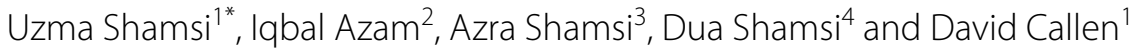

\begin{abstract}
Background: Vitamin D deficiency is becoming a serious public health problem, even in sun-drenched cities like Karachi, Pakistan. We investigated the prevalence of vitamin D deficiency and its association with sociodemographic characteristics, anthropometric measures, and lifestyle factors among premenopausal and postmenopausal women $(n=784)$.
\end{abstract}

Methods: Face-to-face interviews were conducted to collect information and serum concentrations of 25-hydroxyvitamin D were measured after the interviews.

Results: A total of $57 \%$ of women were vitamin D deficient with higher vitamin D deficiency found among premenopausal women (64.7\%) compared to postmenopausal women (49\%). The median serum concentrations of 25-hydroxyvitamin D (IQR) were $16.7 \mathrm{ng} / \mathrm{ml}$ (IQR 9.8-30.0). Factors associated with vitamin D deficiency were lower socioeconomic status (OR 2.00; 95\% Cl 1.15-3.48), younger age with highest vitamin D deficiency found in $<35$ years of age group (OR 3.11; 95\% Cl 1.76-5.51), and winter season (OR 1.51,95\% Cl 1.07-2.15) after adjusting for multiple confounders. The use of vitamin D supplement (OR $0.59,95 \% \mathrm{Cl} 0.38-0.92)$ and vigorous exercise (OR $0.20,95 \% \mathrm{Cl}$ $0.05-0.80$ ) were protective against vitamin D deficiency.

Conclusions: The study shows a high prevalence of vitamin D deficiency, with detrimental health effects, among younger women belonging to lower socioeconomic status and during the winter season. The use of vitamin D supplements and vigorous exercise were protective measures. Public health campaigns are needed for education and awareness about vitamin D deficiency to improve vitamin D status for younger women living in poor environments.

Keywords: Vitamin D deficiency, Socioeconomic status, Postmenopausal, Premenopausal

\section{Background}

Vitamin D deficiency VDD $(<20 \mathrm{ng} / \mathrm{ml})$ is becoming increasingly common in majority of population worldwide. There is also a lot of research interest in studies

*Correspondence: uzma.shamsi@adelaide.edu.au

${ }^{1}$ School of Medicine, Adelaide Medical School, University of Adelaide,

Adelaide, Australia

Full list of author information is available at the end of the article assessing the factors causing VDD and role of VDD in many diseases including the Covid 19 infection $[1,2]$. VDD is an important public health problem in Pakistan too. According to a study in Hyderabad, VDD and vitamin D insufficiency combined was $78.3 \%$ among 1244 healthy individuals [3]. In another study at Ayub Teaching Hospital Abbottabad, high VDD was reported among 202 patients (63.4\%) with complaints of generalized body aches [4]. A study conducted among healthy women of 
child-bearing age in Lahore reported that VDD was 73\%. Factors associated with VDD were lesser sun exposure, illiteracy, winter season during sampling and no usage of multivitamins. A cross-sectional population survey among 300 adult population of Karachi showed median concentration of serum vitamin D as $18.8 \mathrm{ng} / \mathrm{ml}$ with high prevalence of VDD [5]. VDD was reported as $90.1 \%$ among 305 premenopausal females in another crosssectional study in Karachi, Pakistan. Factors associated with VDD were age, city of residence in downtown and suburbs, and type of housing [6]. In a recent study among 221 medical students of a medical school, VDD was found in $89.1 \%$ and factors associated with VDD were limited sun exposure and attire consisting of full length of sleeves outside [7].

There is a lot of variation in the vitamin D status of women living in Karachi in different studies, most of which consisted of smaller sample sizes and only few potential factors responsible for VDD were assessed. Therefore, the objective of the study was to assess the frequency of VDD and investigate all the factors associated with VDD among women of both premenopausal and postmenopausal status in Karachi Pakistan.

\section{Methods}

\section{Study population}

We extracted data of 784 women, who were in the control group and had complete information on potential predictors of VDD and serum 25(OH)D concentrations, from the case control study (the details of which are mentioned in a recently published article) [8]. Briefly, two major hospitals were selected to have a representative sample in Karachi, which is the 5th most populous city in the world: Aga Khan University Hospital (AKUH) is a private teaching hospital in Pakistan and ISO 9002 certified. Karachi Institute of Radiation and Nuclear Medicine Hospital (KIRAN), is a public hospital, which also provides free diagnosis and treatment facilities to more than $75 \%$ of its patients, who come from all over the country. All the women were interviewed attending in- and outpatient services for general medical, and surgical departments. Exclusion criteria were history of any cancer, parathyroid, renal or liver disease, chronic malabsorption syndromes or any known or suspected drug that may alter vitamin $\mathrm{D}$ metabolism.

Face to face interviews were conducted and information was collected about sociodemographic factors, clinical and reproductive history, sun exposure, use of vitamin D supplementation, and anthropometric measurement. Age was categorized into $<35,35-45,46-54,55$ years. Education was categorized as $<8,8-12$, or $>12$ years of education. Socio-economic (SES) factors included multiple variables like education, place and type of residence, home ownership, number of rooms, total household members, total household monthly income and crowding index (the number of household members divided by number of rooms) A composite variable for SES was calculated by factor analysis of all these important variables. Finally, SES was categorized into upper, middle and lower status [8].

\section{Sun exposure measurement questionnaire}

The validated Long-Term Sun Exposure Measurement Questionnaire (LT SEM-Q) was used to assess sun exposure among all women [9]. This questionnaire assessed sunlight exposure, duration of sun exposure, skin tone, use of sunscreens and sun avoidance behaviour. The time spent outdoors between $10 \mathrm{am}$ and $4 \mathrm{pm}$ was asked to calculate approximate amount of time in minutes per week that women were exposed to UVB radiations. Details of weights given to sun exposure variables are in the Additional File 1: Table 1. The final scoring algorithm of sun exposure score in summers and winters was created by multiplying the time (minutes) spent in the sun by the proportions of the different variables. The skin tone of the women was assessed using a shade card (10 skin tones (1-10)) by matching shade of the skin on forehead with the shade on the card, according to LT SEM-Q.

\section{Vitamin D supplements}

Use of vitamin intake was asked in detail including frequency, duration and form of intake as injectable, oral drops or capsules apart from intake as yes vs. no. The use of Vitamin D supplement including multivitamins was assessed by asking participants if they had been taking Vitamin D supplements regularly, occasionally or not at all in their lifetime. Information was also obtained about form and mode of administration (injections, oral tablets/capsules or ampoule drops). Herbal medications which possibly increase Vitamin D inactivation was also taken into consideration. In order to determine if there were possible drug interactions, participants were also asked whether they had taken anti-hypertensive, antiepileptic, anti-inflammatories and endocrine drugs.

\section{Measurement of serum 25(OH)D concentrations}

Venous blood samples $(2.5 \mathrm{ml})$ were taken from all participants and collected in yellow topped gel tubes at the end of the interview. Serum 25(OH)D concentrations were measured by a kit from DiaMetra SRL (Via Garibaldi, 18-20090 Segrate Italy), using solid phase enzymelinked immunoassay (ELISA). The cut-off used to define VDD was according to the Parathyroid Hormone (PTH) 
levels [10].Vitamin D deficiency was defined as a serum $25(\mathrm{OH}) \mathrm{D}$ concentrations $<20 \mathrm{ng} / \mathrm{ml}$. Season of blood collection (winter/ spring vs. summer/fall) was also recorded.

\section{Vitamin D containing food items}

There are limited major sources of vitamin D in the diet. Each participant was asked about following dietary intake of Vitamin D containing food items: milk, yogurt, lassi, eggs, fish (fatty or white fish), any fortified cereals, breads or other products. over the past year. Intake frequency was categorised into 7 groups ranging from "never" to "5-6 times per day" for these foods and beverages. The selected frequency category for each food item was converted to a daily intake. For example, a response of "one serving/week" was converted to 0.14 servings/ day by dividing 1 by 7 . Each participant was also asked about their average portion size/ common serving size of the food. A common serving (svg) size of food item or beverage was specified on the FFQ (e.g. 1 cup of milk or one egg,). The intake frequencies were multiplied by standard portion size to calculate servings per day of all the food items. However, consumption in grams per unit or macronutrient intakes or calories from each food was not calculated.

Physical activity was also measured and the International Physical Activity Questionnaire (IPAQ) index was used [11]. Physical activity was categorized into vigorous exercise like heavy lifting, digging, aerobics and moderate exercise like carrying light loads, mopping etc. that makes one breathe somewhat harder than normal and walking and women recalled the number of days and hours or minutes, they were engaged in physical activity of different intensities for at least ten minutes.

Other variables included BMI (calculated as weight in kilograms divided by the square of height in meters). Women were categorized into three groups according to the World Health Organization (WHO) cut off for BMI in Asian population [12]: a normal weight (18.5-24.9 kg/ $\left.\mathrm{m}^{2}\right)$, being overweight $\left(25.0-29.9 \mathrm{~kg} / \mathrm{m}^{2}\right)$ or obese $\left(>30 \mathrm{~kg} / \mathrm{m}^{2}\right)$.

\section{Statistical analysis}

Mean and standard deviations are reported for continuous variables and frequencies and percentages for categorical variables to illustrate the differences in vitamin D concentrations between premenopausal and postmenopausal women. Univariable analysis was done to calculate unadjusted OR and $95 \%$ CI. Variables $<0.25$ and those variables with biological plausibility were included and entered in multivariable logistic regression in a stepwise fashion to calculate adjusted ORs and 95\% CIs. All reported $p$ values are based on two-sided tests. Statistical analysis of the data was carried out using the SPSS package for Windows 22.0 (SPSS, IBM, Armonk, NY, USA).

\section{Results}

The median concentration of serum 25(OH)D was $16.7 \mathrm{ng} / \mathrm{ml}$ (IQR 9.8-30.0). There was a high prevalence of VDD among both premenopausal and postmenopausal women. Individual $25(\mathrm{OH}) \mathrm{D}$ concentrations ranged from $0.3 \mathrm{ng} / \mathrm{ml}$ to $165.5 \mathrm{ng} / \mathrm{ml}$. The median 25(OH)D concentration was lower among premenopausal women (13.9 ng/ml, IQR 8.0-25.2) compared to postmenopausal women $(20.4 \mathrm{ng} / \mathrm{ml}$, IQR 11.1-31.7).

Women were further categorized into four groups according to the different concentrations of $25(\mathrm{OH})$ $\mathrm{D}$, defined as severely deficient $(<12 \mathrm{ng} / \mathrm{ml})$, deficient (12-19 $\mathrm{ng} / \mathrm{ml})$, insufficient $(20-30 \mathrm{ng} / \mathrm{ml})$ and sufficient $(>30 \mathrm{ng} / \mathrm{ml}$ ) (Table 1$)$. Both severe vitamin D deficiency and deficiency was significantly more frequent in premenopausal women compared to postmenopausal women.

Table 2 shows that VDD was associated with younger age, with highest VDD among women of $<35$ years of age group (adjusted OR 3.11; 95\% CI 1.76-5.51), and lower socioeconomic status (adjusted OR 2.00; 95\% CI 1.153.48 after adjusting for multiple confounders $(p<0.0001)$. Use of vitamin D supplement (adjusted OR 0.59, 95\% CI $0.38-0.92$ ) and vigorous exercise (adjusted OR 0.20, 95\% CI 0.05-0.80) were protective against VDD. As it was a hospital-based study, it was observed that a higher percentage (63\%) of women took vitamin D supplements but fish intake was less frequent and nearly $40 \%$ women

Table 1 Number and percentage of women for different serum 25(OH)D concentrations

\begin{tabular}{|c|c|c|c|c|}
\hline Serum $25(\mathrm{OH}) \mathrm{D}(\mathrm{ng} / \mathrm{ml})$ & $\begin{array}{l}\text { Premenopausal women } n \\
\text { (\%) }\end{array}$ & $\begin{array}{l}\text { Postmenopausal women } \mathrm{n} \\
\text { (\%) }\end{array}$ & All women n (\%) & $p$ value* \\
\hline Severely deficient $(<12)$ & $124(39.9)$ & $78(26.2)$ & $202(33.2)$ & $<0.001$ \\
\hline Deficient (12-19) & $77(24.8)$ & $68(22.8)$ & $145(23.8)$ & \\
\hline Insufficient (20-30) & $52(16.7)$ & $61(20.5)$ & $113(18.6)$ & \\
\hline Sufficient (> 30) & $58(18.6)$ & $91(30.5)$ & $149(24.5)$ & \\
\hline
\end{tabular}

${ }^{*} p$ values generated from Chi-square test 
Table 2 Socio-demographic and clinical characteristics of both premenopausal and postmenopausal women $(n=784)$ according to serum $25(\mathrm{OH})$ D concentrations ( $\mathrm{ng} / \mathrm{ml})$ in Karachi, Pakistan

\begin{tabular}{|c|c|c|c|c|}
\hline Variables & Vitamin $D \geq 20$ & $\begin{array}{l}\text { Vitamin D } \\
\text { deficiency }<20\end{array}$ & Crude OR $(95 \% \mathrm{Cl})$ & Adjusted OR (95\% Cl) \\
\hline Age groups & n (\%) & n (\%) & & \\
\hline$<35$ & $29(10.9)$ & $65(18.7)$ & $3.46(2.00,5.97)$ & $3.11(1.76,5.51)$ \\
\hline $35-45$ & $77(28.9)$ & $144(41.4)$ & $2.88(1.88,4.43)$ & $2.66(1.69,4.19)$ \\
\hline $46-54$ & $69(25.9)$ & $80(23.0)$ & $1.79(1.13,2.83)$ & $1.72(1.07,2.77)$ \\
\hline 55 and above & $91(34.2)$ & $59(17.0)$ & Ref & Ref \\
\hline \multicolumn{5}{|l|}{ Education } \\
\hline$<$ Grade8 & $49(18.4)$ & $68(19.5)$ & $1.07(0.69,1.65)$ & \\
\hline Grades 8-12 & $87(32.7)$ & 111(31.9) & $0.98(0.68,1.41)$ & \\
\hline$>$ Grade12 & $130(48.9)$ & $169(48.6)$ & Ref & \\
\hline \multicolumn{5}{|l|}{ Socioeconomic status } \\
\hline Lower & $61(22.9)$ & $52(14.9)$ & $2.62(1.58,4.34)$ & $2.0(1.15,3.48)$ \\
\hline Middle & $158(59.4)$ & $191(54.9)$ & $1.42(0.92,2.17)$ & $1.23(0.77,1.95)$ \\
\hline Upper & $47(17.7)$ & $105(30.2)$ & Ref & Ref \\
\hline \multicolumn{5}{|l|}{ Parity* } \\
\hline Nullipara & $34(12.8)$ & $59(17.0)$ & $0.82(0.50,1.350$ & \\
\hline $1-3$ & $136(51.1)$ & $152(43.7)$ & $0.64(0.40,1.04)$ & \\
\hline$>3$ & $96(36.1)$ & $137(39.4)$ & Ref & \\
\hline \multicolumn{5}{|l|}{ Menopausal status } \\
\hline Postmenopausal & $152(58.0)$ & $146(43.0)$ & $1.90(1.38,2.63)$ & \\
\hline Premenopausal & $110(42.0)$ & $201(57.0)$ & Ref & \\
\hline \multicolumn{5}{|l|}{ History of any comorbid } \\
\hline Yes & $161(60.5)$ & $168(48.3)$ & $0.61(0.44,0.84)$ & \\
\hline No & $105(39.5)$ & $180(51.7)$ & Ref & \\
\hline \multicolumn{5}{|l|}{ Season vitamin $\mathrm{D}$} \\
\hline Winter & $102(39.2)$ & $167(48.7)$ & $1.47(1.06,2.04)$ & \\
\hline Summer & $158(60.8)$ & $176(51.3)$ & Ref & \\
\hline \multicolumn{5}{|l|}{ Body mass index } \\
\hline Normal & $70(27.9)$ & $80(25.1)$ & Ref & \\
\hline Over weight & $108(43.0)$ & $130(40.8)$ & $1.05(0.69,1.58)$ & \\
\hline Obese & $73(29.1)$ & $109(34.2)$ & $1.31(0.85,2.02)$ & \\
\hline \multicolumn{5}{|l|}{ Fish consumption } \\
\hline No intake & $107(41.2)$ & $136(40.1)$ & $1.14(0.56,2.29)$ & \\
\hline$<$ Than once a month & $136(52.3)$ & $184(54.3)$ & $1.21(0.61,2.42)$ & \\
\hline$\geq$ Once/month & $17(6.5)$ & $19(5.6)$ & Ref & \\
\hline \multicolumn{5}{|c|}{ Vitamin D supplements intake } \\
\hline Yes & $204(76.7)$ & $172(49.4)$ & $0.30(0.19,0.46)$ & $0.59(0.38,0.92)$ \\
\hline No & $62(23.3)$ & $176(50.6)$ & Ref & Ref \\
\hline
\end{tabular}

$O R$ odds ratio; $\mathrm{Cl}$ confidence interval

Parity* was restricted to women who ever had a full-term pregnancy (a pregnancy was considered as full-term if it resulted in a live birth or lasted 7 or more months) ${ }^{a} B M I$ body mass index; BMI was categorized according to the WHO classification for Asian as normal weight $\left(<18.5-24.9 \mathrm{~kg} / \mathrm{m}^{2}\right)$, overweight $\left(25.0-29.9 \mathrm{~kg} / \mathrm{m}^{2}\right)$ or obese $\left(>30 \mathrm{~kg} / \mathrm{m}^{2}\right)$

Reference: OR are compared to those women who had VDD. Adjusted for education, BMI, parity, skin tone, sunlight exposure, attire outside. Reference: OR are compared to those women who had no vitamin D deficiency

ate no fish at all. The detailed analysis of different types of vitamin D supplements and vitamin D containing food items is given in supplementary Tables 2 and 3.
Table 3 shows lifestyle and sun exposure factors related to VDD. Moderate physical activity, consisting of mostly household activities, was most common among women compared to vigorous exercise and 
Table 3 Lifestyle and sun exposure related factors associated with serum 25(OH)D concentrations (ng/ml) in Pakistani women

\begin{tabular}{|c|c|c|c|c|}
\hline Categories & Vitamin $D \geq 20$ (\%) & Vitamin $\mathrm{D}<20 \mathrm{n}(\%)$ & Crude OR $(95 \% \mathrm{Cl})$ & Adjusted OR $(95 \% \mathrm{Cl})$ \\
\hline \multicolumn{5}{|l|}{ Vigorous exercise } \\
\hline$<3.5$ h/week & $17(6.4)$ & $7(2.0)$ & $0.82(0.29,2.28)$ & $0.63(0.21,1.86)$ \\
\hline$>3.5 \mathrm{~h} /$ week & $6(2.3)$ & $10(2.9)$ & $0.25(0.07,0.95)$ & $0.20(0.05,0.80)$ \\
\hline No exercise & $243(91.4)$ & $331(95.1)$ & Ref & Ref \\
\hline \multicolumn{5}{|l|}{ Moderate exercise } \\
\hline$<3.5 \mathrm{~h} / \mathrm{wk}$ & $32(12.0)$ & $58(16.7)$ & $0.59(0.40,0.87)$ & \\
\hline$>3.5 \mathrm{~h} / \mathrm{wk}$ & $54(20.3)$ & $98(28.2)$ & $1.00(0.58,1.72)$ & \\
\hline No exercise & $180(67.7)$ & $192(55.2)$ & Ref & \\
\hline \multicolumn{5}{|l|}{ Walking } \\
\hline$<3.5 \mathrm{~h} / \mathrm{wk}$ & $78(29.3)$ & $88(25.3)$ & $1.59(1.00,2.53)$ & \\
\hline$>3.5 \mathrm{~h} / \mathrm{wk}$ & $46(17.3)$ & $44(12.6)$ & $1.18(0.71,1.97)$ & \\
\hline No exercise & $142(53.4)$ & $216(62.1)$ & Ref & \\
\hline \multicolumn{5}{|l|}{ Head covered } \\
\hline Yes & $171(64.3)$ & $271(78.1)$ & $1.98(1.39,2.83)$ & \\
\hline No & $95(35.7)$ & $76(21.9)$ & Ref & \\
\hline \multicolumn{5}{|l|}{ Face covered } \\
\hline Yes & $39(14.7)$ & $83(23.9)$ & $1.83(1.20,2.79)$ & \\
\hline No & $227(85.3)$ & $264(76.1)$ & Ref & \\
\hline \multicolumn{5}{|l|}{ Neck covered } \\
\hline Yes & $129(48.5)$ & $208(59.9)$ & $1.59(1.15,2.19)$ & \\
\hline No & $137(51.5)$ & $139(40.1)$ & Ref & \\
\hline \multicolumn{5}{|l|}{ Full arm covered } \\
\hline Yes & $166(62.4)$ & $255(73.5)$ & $1.67(1.18,2.36)$ & \\
\hline No & $100(37.6)$ & $92(26.5)$ & Ref & \\
\hline \multicolumn{5}{|l|}{ Half arm covered } \\
\hline Yes & $100(37.6)$ & $88(25.4)$ & $0.56(0.40,0.80)$ & \\
\hline No & $166(62.4)$ & $259(74.6)$ & Ref & \\
\hline \multicolumn{5}{|l|}{ Attire outside } \\
\hline${ }^{*}$ Chadder & $70(26.3)$ & $91(26.3)$ & $1.44(0.95,2.19)$ & \\
\hline **Burqa & $92(34.6)$ & $161(46.5)$ & $1.94(1.33,2.83)$ & \\
\hline Others & $104(39.1)$ & $94(27.2)$ & Ref & \\
\hline \multicolumn{5}{|l|}{ Skin tone } \\
\hline Dark & $151(59.0)$ & $198(59.1)$ & $1.01(0.72,1.42)$ & \\
\hline Wheatish & $93(36.3)$ & $123(36.7)$ & $0.89(0.40,1.98)$ & \\
\hline Fair & $12(4.7)$ & $14(4.2)$ & Ref & \\
\hline \multicolumn{5}{|l|}{ Season of blood draw } \\
\hline Winter & $158(60.8)$ & $176(51.3)$ & $1.47(1.06,2.04)$ & $1.51(1.07,2.15)$ \\
\hline Summer & $102(39.2)$ & $167(48.7)$ & Ref & Ref \\
\hline \multicolumn{5}{|l|}{ Sun avoidance behavior } \\
\hline Yes & $215(80.8)$ & $296(85.3)$ & $1.38(0.90,2.11)$ & \\
\hline No & $51(19.2)$ & $51(14.7)$ & Ref & \\
\hline Sunlight exposure score (summer)* & $26.4(75.6)$ & $32.8(104.7)$ & $10.01(0.97,10.06)$ & \\
\hline Sunlight exposure score (winter)* & $39.9(89.6)$ & $49.1(121.1)$ & $10.02(9.98,10.05)$ & \\
\hline
\end{tabular}

OR odds ratio; $\mathrm{Cl}$ confidence interval

Reference: OR are compared to those women who had VDD

${ }^{*}$ Covering head, neck, full arms and full legs ${ }^{* *}$ Covering head, face, neck, full arms and full legs

Adjusted for education, BMI, parity, skin tone, sunlight exposure, attire outside. Reference: OR are compared to those women who had no vitamin D deficiency 
walking. Vigorous exercise $>3.5$ hors/week, though it was less common among all women, but it was protective against vitamin $\mathrm{D}$ deficiency (adjusted OR 0.20, 95\% CI 0.05-0.80). VDD was also associated with winter season (adjusted OR 1.51, 95\% CI 1.07-2.15). The majority of the women had skin tone of 5 and 6 categorized as wheatish tone, however, skin tone was not associated with serum $25(\mathrm{OH}) \mathrm{D}$ concentrations.

\section{Discussion}

In our study, $57 \%$ of women had VDD and only $24.5 \%$ of participants had optimal vitamin D status. VDD was associated with younger age, lower SES, winter season, while exercise and vitamin D supplement use were protective. A cross-sectional study among 351 patients at the out-patient department of General Medicine of a hospital in Islamabad, reported VDD present in $62.9 \%$ of females (mean age $46.03+/-16.18$ years) and the mean vitamin D concentration was $14.09+/-12.93 \mathrm{ng} / \mathrm{ml}$ [13]. A study conducted in Lahore similarly reported high prevalence of VDD among healthy women of child-bearing and was also associated with low education and lack of proper sun exposure and multivitamin intake [14].

In a study conducted at an urban hospital in Boston, VDD was associated with winter season, higher body mass index, and physical inactivity [15]. In a study in Japan among 4,793 patients with rheumatoid arthritis, the mean $(\mathrm{SD})$ serum $25(\mathrm{OH})$ D concentration was $16.9 \mathrm{ng} / \mathrm{mL}$ (SD 6.1), and the prevalence of vitamin D deficiency was $71.8 \%$. Predictors of VDD were female gender, younger age, among other factors that included low serum concentrations of total protein and total cholesterol, high serum ALP concentrations, and NSAID intake [16]. VDD was also found high among pregnant women in Belgium [17]. Association of VDD with younger age among females has been consistently reported in multiple studies [18-22].

Similar to our study, VDD is found to be more common among women during winter/spring compared with summer/autumn [23-25]. In South Florida (U.S.), the mean $(+/-\mathrm{SD})$ of $25(\mathrm{OH}) \mathrm{D}$ concentration was $22.4+/-8.2 \mathrm{ng} / \mathrm{ml}$ in $40 \%$ of women during winter [26]. In a study in 3,327 pregnant Japanese women, VDD prevalence was $73.2 \%$ and it was higher in April after the winter season. Sun exposure of $>15 \mathrm{~min}$ for 1-2 days / week and usage of dietary vitamin $\mathrm{D}$ were protective against VDD [27]. A study conducted in Jinnah Postgraduate Medical Center, Karachi among students also showed that VDD was more common in winter [28]. Similarly, a cross-sectional study of 14,302 Chinese participants aged 18-65 years from six major cities in China reported VDD was higher among females, in spring and winter from certain residential regions [29].
A study conducted among pregnant women in Malaysia reported that intake of vitamin $\mathrm{D}$ was protective against VDD. However, it reported no association of VDD with age, educational, SES, employment, parity, body mass index, and sun exposure [30]. Another small crosssectional study in Riyadh, Saudi Arabia, reported VDD among $60.2 \%$ of participants was associated with lack of usage of vitamin D, and multivitamins [31]. Another study in Riyadh, Saudi Arabia reported that absence of vitamin $D$ supplements usage, younger age were factors associated with VDD among females [32]. VDD was $75.1 \%$ in a study in France and was associated with lack of intake of vitamin D [33]. A cross-sectional study of 634 healthy volunteers aged $18-50$ years reported VDD associated with lack of multivitamin use $(p<0.001)$ [34].

Our study showing lower SES and sedentary lifestyle associated with VDD was also reported by The National Health and Nutrition Examination Survey (NHANES) 2001-2010 [35]. A cross-sectional study in Saudi Arabia, reported younger age, less exercise, less Vitamin D intake, as predictors of VDD [36].

Our study results are consistent with findings in few other studies conducted in Switzerland, China and New South Wales showing association of VDD with childbearing age, winter season and no usage of vitamin D supplement [37-39]. A large study from the Korean National Health and Nutrition Examination Survey (KNHANES) 2008-2009 among 2062 adolescents also showed that VDD was higher in senior high school students and was associated with winter season and parental vitamin D deficiency [40].

Contrary to previous studies across different ethnic backgrounds, this study within Pakistani females showed that certain factors like skin tone, obesity, sun exposure etc. were not associated with VDD. However, this lack of association between VDD and BMI was also observed in a study in Lebanon [41]. The lack of association between VDD and sun exposure is also reported in a study in Brazil, where the use of sun exposure questionnaire with 25OHD concentration showed low accuracy and its lack of discrimination between vitamin D sufficient and deficient individuals [42]. A cross-sectional study among 254 university students in Shiraz also showed no association between VDD and sun exposure[43]. The possible explanation could be that it is difficult to recall and answer to the questions related to sun exposure accurately. Moreover, there was no association found between dietary sources of vitamin D and VDD. One reason could be the low consumption of fish and milk and vitamin D fortified food items in our population.

Our study has several strengths. The study collected comprehensive information on all potential factors associated with VDD. The data was collected by trained 
medical officers with expertise in both medical history taking and research. The main weakness of the study is the recall bias which is inherent in any cross sectional or case control study. Intake of vitamin D supplements use was self-reported, and most of the participants were unable to recall exact dosages and durations of vitamin D usage. Another limitation of the study is that it has a limited generalizability as it was a representative sample of women coming to both private and public hospitals, but not representative of the healthy women in general population.

Public awareness and educational campaigns about the importance of adequate vitamin D concentrations, are needed with importance of sensible sunlight exposure, adequate nutritional intake of vitamin D-rich foods and vitamin D supplements to prevent adverse health outcomes related to VDD.

\section{Abbreviations}

Cl: Confidence interval; VDD: Vitamin D deficiency; OR: Odds ratio; AKU: Aga Khan University.

\section{Supplementary Information}

The online version contains supplementary material available at https://doi. org/10.1186/s12905-021-01339-9.

Additional File 1. Table 1 1shows sun exposure varaibles details.

\section{Acknowledgements}

None.

\section{Authors' contributions}

US participated in the design of the study, acquisition of data, performed the statistical analysis, and drafted the manuscript. DC made substantial contributions to conception and design, interpretation of data, acquisition of data, and interpretation of data. IA performed the statistical analysis and contributed to interpretation of data. AS \& DS made contribution to manuscript writing and proofreading it. All authors were involved in revising the manuscript critically for important intellectual content, and final approval of the version to be published.

\section{Funding}

This work was supported by the Deans fund Aga Khan University Hospital Grant (201710550 2025150081001 0000). The funding bodies were not involved in the design of this study or in the collection of data, analysis, and interpretation of results.

\section{Availability of data and materials}

The datasets used and analyzed during the current study are available from the corresponding author on request.

\section{Declarations}

\section{Ethics approval and consent to participate}

The study was performed in accordance with the ethical standards of the Declaration of Helsinki (1964) and its subsequent amendments. The ethical approval was obtained by the Human Research Ethics Committee of the University of Adelaide, Australia (H-2014-111) and the Ethical Review Committees of Aga Khan University Hospital, Karachi Pakistan (3074-CHS-ERC-14). Informed consent was obtained using the Patient Information Sheet and Consent form.
Participants were clearly informed about the objectives and procedures of the study, their rights and commitments, and the benefits and risks involved. If the patients agreed to participate, they were asked to sign the consent paper. The consent form of the study was provided both in English and the local language of Urdu. If unable to read the consent form, the form was read out to participants and informed consent was taken verbally.

\section{Consent for publication}

Not applicable.

\section{Competing interests}

The authors declare that they have no conflict of interest.

\section{Author details}

${ }^{1}$ School of Medicine, Adelaide Medical School, University of Adelaide, Adelaide, Australia. ${ }^{2}$ Department of Community Health Sciences, Aga Khan University, Karachi, Pakistan. ${ }^{3}$ Department of Gynecology and Obstetrics, Combined Military Hospital, Karachi, Pakistan. ${ }^{4}$ Division of Data Science, University of California, Berkeley, USA.

Received: 20 January 2021 Accepted: 27 April 2021

Published online: 10 May 2021

\section{References}

1. Mariani J, Gimenez VMM, Bergam I, Tajer C, Antonietti L, Inserra F, et al. Association between vitamin D deficiency and COVID-19 incidence, complications, and mortality in 46 countries: an ecological study. Health Secur. 2020.

2. Meltzer DO, Best TJ, Zhang H, Vokes T, Arora V, Solway J. Association of vitamin D status and other clinical characteristics with COVID-19 test results. JAMA Netw Open. 2020;3(9):e2019722.

3. Kandhro F, Dahot U, Naqvi SHA, Ujjan IU. Study of Vitamin D deficiency and contributing factors in the population of Hyderabad, Pakistan. Pak J Pharm Sci. 2019;32(3):1063-8.

4. Jadoon SA, Ahmed A, Alam MA. Vitamin D deficiency in Pakistan: tip of Iceberg. J Ayub Med Coll Abbottabad. 2018;30(1):78-80.

5. Sheikh A, Saeed Z, Jafri SA, Yazdani I, Hussain SA. Vitamin D levels in asymptomatic adults - a population survey in Karachi, Pakistan. PLoS ONE. 2012;7(3):e33452.

6. Khan AH, labal R, Naureen G, Dar FJ, Ahmed FN. Prevalence of vitamin $D$ deficiency and its correlates: results of a community-based study conducted in Karachi, Pakistan. Arch Osteoporos. 2012;7:275-82.

7. Nadeem S, Munim TF, Hussain HF, Hussain DF. Determinants of Vitamin D deficiency in asymptomatic healthy young medical students. Pak J Med Sci. 2018;34(5):1248-52

8. Shamsi U, Khan S, Azam I, Habib Khan A, Maqbool A, Hanif M, et al. A multicenter case control study of association of vitamin D with breast cancer among women in Karachi, Pakistan. PLoS ONE. 2020;15(1):e0225402.

9. Humayun Q, labal R, Azam I, Khan AH, Siddiqui AR, Baig-Ansari N. Development and validation of sunlight exposure measurement questionnaire (SEM-Q) for use in adult population residing in Pakistan. BMC Public Health. 2012;12:421.

10. Holick MF. Vitamin D deficiency. N Engl J Med. 2007;357(3):266-81.

11. Bassett DR Jr. International physical activity questionnaire: 12-country reliability and validity. Med Sci Sports Exerc. 2003:35(8):1396.

12. Obesity: preventing and managing the global epidemic. Report of a WHO consultation. World Health Organ Tech Rep Ser. 2000;894:i-xii, $1-253$.

13. Kiani IG, Shah F, Mansur SS. Frequency of severe vitamin-D deficiency in patients presenting to a tertiary care hospital in Islamabad. J Pak Med Assoc. 2014;64(10):1138-40.

14. Junaid K, Rehman A, Jolliffe DA, Wood K, Martineau AR. High prevalence of vitamin $D$ deficiency among women of child-bearing age in Lahore Pakistan, associating with lack of sun exposure and illiteracy. BMC Womens Health. 2015;15:83.

15. Gordon CM, DePeter KC, Feldman HA, Grace E, Emans SJ. Prevalence of vitamin D deficiency among healthy adolescents. Arch Pediatr Adolesc Med. 2004;158(6):531-7. 
16. Furuya T, Hosoi T, Tanaka E, Nakajima A, Taniguchi A, Momohara S, et al. Prevalence of and factors associated with vitamin D deficiency in 4,793 Japanese patients with rheumatoid arthritis. Clin Rheumatol. 2013;32(7):1081-7.

17. Vandevijvere S, Amsalkhir S, Van Oyen H, Moreno-Reyes R. High prevalence of vitamin $D$ deficiency in pregnant women: a national crosssectional survey. PLoS ONE. 2012;7(8):e43868.

18. Richard A, Rohrmann S, Quack Lotscher KC. Prevalence of vitamin D deficiency and its associations with skin color in pregnant women in the first trimester in a sample from Switzerland. Nutrients. 2017;9(3).

19. Fang F, Wei H, Wang K, Tan L, Zhang W, Ding L, et al. High prevalence of vitamin D deficiency and influencing factors among urban and rural residents in Tianjin, China. Arch Osteoporos. 2018;13(1):64.

20. Lopes VM, Lopes JR, Brasileiro JP, Oliveira I, Lacerda RP, Andrade MR, et al. Highly prevalence of vitamin D deficiency among Brazilian women of reproductive age. Arch Endocrinol Metab. 2017;61(1):21-7.

21. Mehboobali N, Iqbal SP, Iqbal MP. High prevalence of vitamin D deficiency and insufficiency in a low income peri-urban community in Karachi. J Pak Med Assoc. 2015;65(9):946-9.

22. Kaptein EM, Yi SS, Endres DB, Kaptein JS, Chan LS. Vitamin D deficiency in urban indigent patients in Southern California. Endocr Pract. 2013;19(3):404-13.

23. Horton-French K, Dunlop E, Lucas RM, Pereira G, Black LJ. Prevalence and predictors of vitamin D deficiency among African immigrants living in Australia. Int J Environ Res Public Health. 2019;16(16).

24. Malacova E, Cheang PR, Dunlop E, Sherriff JL, Lucas RM, Daly RM, et al. Prevalence and predictors of vitamin $D$ deficiency in a nationally representative sample of adults participating in the 2011-2013 Australian Health Survey. Br J Nutr. 2019;121(8):894-904.

25. Al Zarooni AAR, Al Marzouqi Fl, Al Darmaki SH, Prinsloo EAM, Nagelkerke N. Prevalence of vitamin D deficiency and associated comorbidities among Abu Dhabi Emirates population. BMC Res Notes. 2019;12(1):503.

26. Levis S, Gomez A, Jimenez C, Veras L, Ma F, Lai S, et al. Vitamin d deficiency and seasonal variation in an adult South Florida population. J Clin Endocrinol Metab. 2005:90(3):1557-62.

27. Kanatani KT, Nakayama T, Adachi Y, Hamazaki K, Onishi K, Konishi Y, et al. High frequency of vitamin D deficiency in current pregnant Japanese women associated with UV avoidance and hypo-vitamin D diet. PLoS ONE. 2019;14(3):e0213264.

28. Raza A, Syed JG, Muhammad Ali F, Danish Khan M, Ali Khan M, Haleem F, et al. Incidence of vitamin D deficiency in different seasons in the adult Karachi population presenting in the medical outpatient department with generalized body ache. Cureus. 2019;11(7):e5167.

29. Jiang W, Wu DB, Xiao GB, Ding B, Chen EQ. An epidemiology survey of vitamin D deficiency and its influencing factors. Med Clin (Barc). 2020;154(1):7-12.

30. Woon FC, Chin YS, Ismail IH, Batterham M, Abdul Latiff AH, Gan WY, et al. Vitamin D deficiency during pregnancy and its associated factors among third trimester Malaysian pregnant women. PLoS ONE. 2019;14(6):e0216439.

31. AlFaris NA, AlKehayez NM, AIMushawah FI, AINaeem AN, AlAmri ND, AlMudawah ES. Vitamin D Deficiency and Associated Risk Factors in Women from Riyadh, Saudi Arabia. Sci Rep. 2019;9(1):20371.

32. AlQuaiz AM, Kazi A, Fouda M, Alyousefi N. Age and gender differences in the prevalence and correlates of vitamin D deficiency. Arch Osteoporos. 2018;13(1):49.

33. Deplanque $X$, Wullens $A$, Norberciak L. Prevalence and risk factors of vitamin D deficiency in healthy adults aged 18-65 years in northern France. Rev Med Intern. 2017;38(6):368-73.

34. Mitchell DM, Henao MP, Finkelstein JS, Burnett-Bowie SA. Prevalence and predictors of vitamin D deficiency in healthy adults. Endocr Pract. 2012;18(6):914-23.

35. Liu X, Baylin A, Levy PD. Vitamin D deficiency and insufficiency among US adults: prevalence, predictors and clinical implications. Br J Nutr. 2018;119(8):928-36.

36. Alloubani A, Akhu-Zaheya L, Samara R, Abdulhafiz I, Saleh A, Altowijri A. Relationship between vitamin D deficiency, diabetes, and obesity. Diabetes Metab Syndr. 2019;13(2):1457-61.

37. Krieger JP, Cabaset S, Canonica C, Christoffel L, Richard A, Schroder T, et al. Prevalence and determinants of vitamin D deficiency in the third trimester of pregnancy: a multicentre study in Switzerland. Br J Nutr. 2018;119(3):299-309.

38. Ning Z, Song S, Miao L, Zhang P, Wang X, Liu J, et al. High prevalence of vitamin $D$ deficiency in urban health checkup population. Clin Nutr. 2016;35(4):859-63.

39. Quaggiotto $P$, Tran $H$, Bhanugopan M. Vitamin D deficiency remains prevalent despite increased laboratory testing in New South Wales. Austr Singapore Med J. 2014;55(5):271-80.

40. Kim SH, Oh MK, Namgung R, Park MJ. Prevalence of 25-hydroxyvitamin $D$ deficiency in Korean adolescents: association with age, season and parental vitamin D status. Public Health Nutr. 2014;17(1):122-30.

41. Al Hayek S, Matar Bou Mosleh J, Ghadieh R, El Hayek Fares J. Vitamin D status and body composition: a cross-sectional study among employees at a private university in Lebanon. BMC Nutr. 2018;4:31.

42. Bittar FB, Castro CHM, Szejnfeld VL. Screening for vitamin D deficiency in a tropical area: results of a sun exposure questionnaire. BMC Endocr Disord. 2018;18(1):44

43. Faghih S, Abdolahzadeh M, Mohammadi M, Hasanzadeh J. Prevalence of vitamin d deficiency and its related factors among university students in Shiraz, Iran. Int J Prev Med. 2014;5(6):796-9.

\section{Publisher's Note}

Springer Nature remains neutral with regard to jurisdictional claims in published maps and institutional affiliations.
Ready to submit your research? Choose BMC and benefit from:

- fast, convenient online submission

- thorough peer review by experienced researchers in your field

- rapid publication on acceptance

- support for research data, including large and complex data types

- gold Open Access which fosters wider collaboration and increased citations

- maximum visibility for your research: over $100 \mathrm{M}$ website views per year

At BMC, research is always in progress.

Learn more biomedcentral.com/submissions 